\title{
FAKTOR-FAKTOR YANG MEMPENGARUHI STRES AKADEMIK MAHASISWA KEPERAWATAN
}

\author{
Factors that Influence the Academic Stress of Nursing Students
}

\author{
Nety Mawarda Hatmanti, Yurike Septianingrum \\ Program Studi S1 Keperawatan UNUSA \\ nety.mawarda@unusa.ac.id
}

\begin{abstract}
ABSTRAK
Tingkat stress yang dialami oleh remaja cenderung tinggi dan bias menimbulkan dampak negative. Penelitian ini bertujuan untuk mengetahui factor-faktor yang mempengaruhi stress akademik mahasiswa keperawatan. Desain dalam penelitian ini menggunakan metode deskriptif analitik dengan pendekatan Cross Sectional. Populasi penelitian ini adalah 595 mahasiswa Prodi s1 Keperawatan di semester 1, 3, 5 dan 7. Pengambilan sampel menggunakan tehnik Cluster Sampling sehingga didapatkan jumlah sampel = 240 mahasiswa dari 4 tingkat. Hasil penelitian menunjukkan bahwa sebagian besar mahasiswa berada dalam kategori tingkat stress berat(62\%). Uji menggunakan Pearson Chi Square didapatkan hasil bahwa pertumbuhan fisik tidak berhubungan dengan tingkat stres $(p$-value $=0,702)$ dan manajemen waktu tidak berhubungan dengan tingkat stres $(p$-value $=$ 0,947). Stres akademik sebaiknya tetap diantisipasi dan dikelola dengan baik, sehingga mahasiswa yang mengalami stress akademik dapat memberikan pengaruh yang positif (adaptif). Pertumbuhan fisik yang baik dan manajemen waktu yang baik akan membantu mahasiswa untuk lebih terarah dalam menjalani perkuliahan sehingga bisa mendukung mahasiswa untuk bersikap adaptif.
\end{abstract}

Kata Kunci :mahasiswa, stress akademik, pertumbuhan fisik, manajemen waktu

\section{ABSTRACT}

Stress level among adolescents are higher and giving negative effect. This study purpose to know about factors that influence the academic stress of nursing students. This study is analitic descriptive with cross sectional approach. This research population is 595 nursing students in 1, 3, 5 and 7 semester. Sampling using cluster sampling technique and get the number of samples are 240 students. Result showed that most of the students $(62 \%)$ have severe stress level. Pearson Chi Square results showed that physical growth is not related to stress level in students and time management not related to stress level. Academic stress should be anticipated and managed properly, so that students who experience academic stress can have positif (adaptive) influence. Physical growth and time management will help students to be more focused in lectures activity so that they can supports students to be adaptive.

Keywords : student college, academic stress, physical growth, time management

\section{PENDAHULUAN}

Mahasiswa merupakan kelompok khusus dimana mereka saat ini berada pada fase transisi dan kritis sebelum menjalani kehidupan yang sebenarnya di masyarakat. Pada fase ini mereka dihadapkan pada tekanan ganda yaitu menuntut ilmu dan ada yang bekerja. Mahasiswa pada masa ini akan mengalami masa transisi dimana banyak tekanan dari sekitarnya diantaranya interaksi dengan orang lain, tekanan untuk belajar, masalah dengan dosen, teman dan keluarga, masalah kesehatan diri sendiri, adaptasi lingkungan baru dan lain sebagainya dimana keadaan ini bisa memicu timbulnya stres dalam kehidupannya. (Hou, Linping, Liu, Yaozhong, 2016).

Zyga (2013) dalam Astarini, Made Indra Ayu, dkk (2017) menyatakan bahwa stres dan kepribadian dapat berpengaruh terhadap perkembangan akademik dan cara beradaptasi. Seseorang yang melanjutkan pendidikan ke perguruan tinggi akan mengalami hal baru dimana akan muncul kepentingan baru dimana stimulus yang mendominasi kehidupan seharihari mahasiswa yang akan dirasakan berat sebelum masuk ke tingkat tiga. 
Berdasarkan hasil penelitian yang dilakukan oleh Purwati, Susi (2012) pada mahasiswa Ilmu Keperawatan Universitas Indonesia didapatkan data bahwa sebagian besar teridentifikasi dalam tingkat stres sedang dan didominasi oleh perempuan. Peneliti melakukan studi pendahuluan pada mahasiswa semester 3 tahun ajaran 2017/2018 sebanyak 10 orang perempuan pada bulan Februari dengan tehnik wawancara tentang perasaan mereka di saat kuliah dan didapatkan data bahwa mereka sering merasakan lelah saat kuliah (2 orang) dan pada saat kuliah sulit berkonsentrasi (8 orang). Hal yang ditunjukkan oleh mahasiswa tersebut merupakan salah satu dari gejala stres. Hasil juga menununjukkan 5 dari 10 orang mahasiswi yang dilakukan wawancara tidak tinggal bersama keluarga mereka (kos).

Studi penelitian sebelumnya menunjukkan bahwa kejadian yang menimbulkan dampak stres dan penuh tekanan mempunyai akibat terhadap kesejahteraan pada diri remaja (Qiaoqiao Fu, Baojuan Ya, Zhonglin Wen, 2012). Kejadian negatif yang menimbulkan efek stres pada kehidupan dapat menimbulkan berbagai dampak yang berbeda pada setiap individu mulai dari keadaan fisiologis dan psikologis. Mengingat para mahasiswa berada pada rentang fisiologis dan psikologis yang khas pada fase kehidupannya, maka kejadian negatif atau yang menimbulkan stres dalam kehidupannya akan berdampak pada kehidupan sehari-hari.

Teori lain menyebutkan bahwa tuntutan dalam proses kehidupan yang berlangsung lama dan tidak ada penyelesaiannya akan menimbulkan dampak terjadinya gangguan psikologis yang salah satunya disebut dengan stres. Seseorang yang mengalami stres akan menunjukkan beberapa gangguan diantaranya cemas, takut, sedih, gelisah, gugup, gangguan fisik berupa sulit tidur, tidak nafsu makan, jantung berdebar, badan merinding dan gejala intelektual seperti sulit berkonsentrasi, daya ingat menurun, pikiran hanya dipenuhi satu pikiran saja. (Braham, 1990)

Berdasarkan fenomena di atas maka peneliti tertarik untuk menganalisis faktorfaktor yang mempengaruhi stres akademik mahasiswa Prodi S1 Keperawatan Fakultas
Keperawatan dan Kesehatan Universitas Nahdlatul Ulama Surabaya.

\section{METODE}

Penelitian ini menggunakan metode deskriptif analitik dengan pendekatan Cross Sectional. Populasi penelitian ini adalah mahasiswa aktif Program Studi S1 Keperawatan Fakultas Keperawatan dan Kebidanan UNUSA tahun akademik 2018/2019 yang berjumlah 595 mahasiswa. Pengambilan sampel dilakukan dengan menggunakan tehnik Cluster Sampling, sehingga didapatkan jumlah sampel sebanyak 240 mahasiswa yang terdiri dari semester 1, 3, 5 dan 7. Pengukuran variable dalam penelitian ini diantaranya : tingkat stress menggunakan kuesioner DASS (Depression Anxiety Stress Scale) yang dimodifikasi, Pertumbuhan Fisik (IMT) dengan observasi tinggi badan dan berat badan, dan Manajemen Waktu diukur menggunakan kuesioner TMQ (Time Management Questionnaire)

\section{HASIL DAN PEMBAHASAN HASIL}

Hasil dalam penelitian ini ada data umum dan data umum. Data umum terdiri dari jenis kelamin, tempat tinggal selama perkuliahan dan kegiatan selain perkuliahan. Data khusus terdiri dari : tingkat stress akademik, IMT (Indeks Massa Tubuh) dan Manajemen Waktu.

1. Data Umum

a. Jenis Kelamin

Tabel 1 Distribusi Frekuensi Responden menurut Jenis Kelamin

\begin{tabular}{cccc}
\hline No & $\begin{array}{c}\text { Jenis } \\
\text { Kelamin }\end{array}$ & Frekuensi & $\begin{array}{c}\text { Persentase } \\
(\%)\end{array}$ \\
\hline 1. & Laki-laki & 24 & 10 \\
2. & Perempuan & 216 & 90 \\
\hline & Total & 240 & $100 \%$ \\
\hline
\end{tabular}

Sumber: Data Primer, 2018

Tabel 1 menunjukkan bahwa dari 240 responden didapatkan hampir seluruhnya $(90 \%)$ berjenis kelamin perempuan. 
b. Tempat Tinggal selama Perkuliahan

Tabel 2 Distribusi Frekuensi Responden menurut tempat tinggal selama perkuliahan

\begin{tabular}{|c|c|c|c|}
\hline No & $\begin{array}{l}\text { Tempat } \\
\text { Tinggal } \\
\end{array}$ & Frekuensi & $\begin{array}{c}\text { Persentase } \\
(\%)\end{array}$ \\
\hline 1. & $\begin{array}{l}\text { Rumah } \\
\text { orang tua }\end{array}$ & 144 & 60 \\
\hline 2. & $\begin{array}{l}\text { Rumah } \\
\text { saudara }\end{array}$ & 12 & 5 \\
\hline 3. & Kost & 65 & 27 \\
\hline 4. & Asrama & 7 & 3 \\
\hline 5. & Kontrak & 7 & 3 \\
\hline 6. & $\begin{array}{l}\text { Rumah } \\
\text { sendiri }\end{array}$ & 5 & 2 \\
\hline \multicolumn{2}{|r|}{ Total } & 240 & $100 \%$ \\
\hline
\end{tabular}

Sumber : Data Primer, 2018

Tabel 2 menunjukkan bahwa dari 240 responden didapatkan sebagian besar (60\%) selama perkuliahan tinggal bersama dengan orang tuanya.

3. Kegiatan selain Perkuliahan

Tabel 3 Distribusi frekuensi responden menurut kegiatan selain perkuliahan

\begin{tabular}{cccc}
\hline No & Kegiatan & Frekuensi & $\begin{array}{c}\text { Persentase } \\
(\%)\end{array}$ \\
\hline 1. & $\begin{array}{c}\text { Organisasi } \\
\text { kampus }\end{array}$ & 130 & 54 \\
2. & $\begin{array}{c}\text { Organisasi } \\
\text { luar } \\
\text { kampus }\end{array}$ & 28 & 12 \\
3. & Bekerja & 10 & 4 \\
4. & $\begin{array}{c}\text { Tidak ada } \\
\text { kegiatan }\end{array}$ & 36 & 15 \\
5. & Lain-lain & 36 & 15 \\
\hline & Total & 240 & $100 \%$ \\
\hline
\end{tabular}

Sumber : Data Primer, 2018

Tabel 3 menunjukkan bahwa dari 240 responden didapatkan sebagian besar (54\%) selama perkuliahan mengikuti kegiatan organisasi di kampus.
4. Pertumbuhan Fisik (IMT/ Indeks Massa Tubuh)

Tabel 4 Distribusi frekuensi responden menurut Pertumbuhan Fisik (IMT)

\begin{tabular}{cccc}
\hline No & $\begin{array}{c}\text { Kategori } \\
\text { IMT }\end{array}$ & Frekuensi & $\begin{array}{c}\text { Persentase } \\
(\%)\end{array}$ \\
\hline 1. & $\begin{array}{c}\text { Berat } \\
\text { badan } \\
\text { kurang }\end{array}$ & 43 & 18 \\
2. & Normal & 147 & 61 \\
3. & $\begin{array}{c}\text { Pra- } \\
\text { obesitas }\end{array}$ & 43 & 18 \\
4. $\quad \begin{array}{c}\text { Obesitas } \\
\text { tingkat } 1\end{array}$ & 7 & 3 \\
5. & $\begin{array}{c}\text { Obesitas } \\
\text { tingkat } 2\end{array}$ & 0 & 0 \\
6. & $\begin{array}{c}\text { Obesitas } \\
\text { tingkat 3 }\end{array}$ & 0 & 0 \\
\hline & Total & 240 & $100 \%$ \\
\hline
\end{tabular}

Sumber : Data Primer, 2018

Tabel 4 menunjukkan bahwa dari 240 responden didapatkan sebagian besar $(61 \%)$ berada pada kategori Indeks Massa Tubuh normal.

\section{Manajemen Waktu}

Tabel 5 Distribusi frekuensi responden menurut manajemen waktu

\begin{tabular}{cccc}
\hline No & Kegiatan & Frekuensi & $\begin{array}{c}\text { Persentase } \\
(\%)\end{array}$ \\
\hline 1. & Baik & 36 & 15 \\
2. & Tidak baik & 204 & 85 \\
\hline & Total & 240 & $100 \%$
\end{tabular}

Sumber : Data Primer, 2018

Tabel 5 menunjukkan bahwa dari 240 responden didapatkan hampir seluruhnya $(85 \%)$ mempunya manajemen waktu yang tidak baik.

2. Data Khusus

a. Tingkat Stres Akademik 
Tabel 6 Distribusi frekuensi responden menurut tingkat stress akademik

\begin{tabular}{cccc}
\hline No & $\begin{array}{c}\text { Kategori } \\
\text { Stres }\end{array}$ & Frekuensi & $\begin{array}{c}\text { Persentase } \\
(\%)\end{array}$ \\
\hline 1. & Normal & 5 & 2 \\
2. & $\begin{array}{c}\text { Tingkat } \\
\text { stress } \\
\text { ringan } \\
\text { Tingkat } \\
\text { stress } \\
\text { sedang } \\
\text { 3. }\end{array}$ & 2 & 1 \\
Tingkat & 48 & 20 \\
4tress berat & 149 & 62 \\
Tingkat & & \\
stress & sangat \\
berat & 36 & 15 \\
\hline & Total & 240 & $100 \%$ \\
\hline
\end{tabular}

Sumber : Data Primer, 2018

Tabel 6 menunjukkan bahwa dari 240 responden didapatkan sebagian besar (62\%) berada pada rentang tingkat stress berat.

b. Hubungan Pertumbuhan Fisik (IMT) dengan Tingkat Stres

Tabel 7 Hasil uji hubungan pertumbuhan fisik dengan tingkat stress

\begin{tabular}{cccc}
\hline $\begin{array}{c}\text { Statistik } \\
\text { Uji }\end{array}$ & Nilai $\chi 2$ & Db & $p$-value \\
\hline $\begin{array}{c}\text { Pearson } \\
\text { Chi- }\end{array}$ & 16,229 & 20 & 0,702 \\
Square & & & \\
\hline
\end{tabular}

Tabel 7 menunjukkan bahwa dari hasil uji Pearson Chi-Square dengan nilai kemaknaan $\alpha$ $=0,05$, didapatkan nilai $\mathrm{p}$-value $=0,702$ yang berarti $\mathrm{p}$-value $>\alpha$ maka $\mathrm{H}_{1}$ ditolak, artinya pertumbuhan fisik (IMT) tidak berhubungan dengan tingkat stres pada mahasiswa Program Studi S1 Keperawatan Fakultas Keperawatan Universitas Nahdlatul Ulama Surabaya.

c. Hubungan Manajemen Waktu dengan Tingkat Stres

Tabel 8 Hasil Uji Hubungan manajemen waktu dengan tingkat stress

\begin{tabular}{cccc}
\hline $\begin{array}{c}\text { Statistik } \\
\text { Uji }\end{array}$ & Nilai $\chi^{2}$ & $\mathrm{Db}$ & $p$-value \\
\hline
\end{tabular}

\begin{tabular}{cccc}
\hline $\begin{array}{c}\text { Pearson } \\
\text { Chi- } \\
\text { Square }\end{array}$ & 0,737 & 4 & 0,947 \\
\hline
\end{tabular}

Tabel 8 menunjukkan bahwa dari hasil uji Pearson Chi-Square dengan nilai kemaknaan $\alpha$ $=0,05$, didapatkan nilai $\mathrm{p}$-value $=0,947$ yang berarti $\mathrm{p}$-value $>\alpha$ maka $\mathrm{H}_{1}$ ditolak, artinya manajemen waktu tidak berhubungan dengan tingkat stres pada mahasiswa Program Studi S1 Keperawatan Fakultas Keperawatan Universitas Nahdlatul Ulama Surabaya.

\section{PEMBAHASAN}

1. Tingkat Stres Akademik Mahasiswa Berdasarkan tabel 6 menunjukkan bahwa sebagian besar (62\%) mahasiswa berada pada rentang tingkat stres berat. Hal ini diperoleh dari jawaban responden saat mengisi kuesioner yang diberikan oleh peneliti. Tingkat stres akademik yang dialami oleh mahasiswa Program Studi S1 Keperawatan Fakultas Keperawatan dan Kebidanan Universitas Nahdlatul Ulama Surabaya berada dalam kategori yang perlu mendapatkan antisipasi dan penatalaksanaan. Hal ini dibuktikan bahwa > 50\% mahasiswa berada dalam kategori stres akademik tingkat berat. Pernyataan ini juga didukung oleh penelitian sebelumnya yang dilakukan oleh Agola dan Ongori (2009) yang menyatakan bahwa tingkat stres akademik pada remaja (dalam penelitian ini termasuk tahap remaja akhir) yaitu mahasiswa tergolong tinggi. Tingkat stres akademik dalam penelitian ini diukur berdasarkan indikator fisik, psikologis/ emosi dan indikator perilaku. Peneliti tidak memunculkan data dari 3 indikator tersebut, hal manakah yang paling tinggi nilainya.

Tingkat stres akademik yang dialami oleh mahasiswa perlu mendapatkan antisipasi dan penatalaksanaan. Psychology Foundation of Australia (2010) menyatakan bahwa pada saat mahasiswa dalam kondisi stres berat maka mahasiswa akan menunjukkan beberapa hal diantaranya : merasa tidak dapat merasakan perasaan positif, merasa tidak kuat lagi untuk melakukan suatu kegiatan, 
merasa tidak ada hal yang dapat diharapkan di masa depan, sedih dan tertekan, putus asa, kehilangan minat akan segala hal, merasa tidak berharga sebagai seorang manusia, berpikir bahwa hidup tidak bermanfaat. Oleh karena itu semakin meningkat stres yang dialami oleh mahasiswa secara bertahap maka hal tersebut bisa menurunkan energi dan respon adaptif.

Tingkat stres akademik dalam kategori normal dan ringan masih dapat meningkatkan motivasi mahasiswa dalam proses pembelajaran di kampus. Potter \& Perry (2005) menyatakan bahwa tingkat stres kategori sedang sampai dengan berat dapat menghambat proses pembelajaran. Hal tersebut juga menjadi penyebab mahasiswa menjadi tidak mampu dalam memusatkan perhatian ataupun konsentrasi mengerjakan sesuatu, seperti tugas perkuliahan. Widianti (2007) menyatakan bahwa beban stres yang dirasa berat juga akan memicu seorang remaja untuk berperilaku negatif, contohnya merokok, alkohol, tawuran, seks bebas sampai ke arah penyalahgunaan NAPZA.

2. Pertumbuhan Fisik dengan Tingkat Stres Berdasarkan penelitian menunjukkan bahwa dari 240 responden didapatkan hampir setengahnya $(39,6 \%)$ mempunyai pertumbuhan fisik (IMT) dalam kategori normal memiliki tingkat stres berat. Tabel 7 menunjukkan bahwa dari hasil uji Pearson Chi-Square dengan nilai kemaknaan $\alpha=0,05$, didapatkan nilai $\mathrm{p}$ value $=0,702$ yang berarti $\mathrm{p}$-value $>\alpha$ maka $\mathrm{H}_{1}$ ditolak, artinya pertumbuhan fisik (IMT) tidak berhubungan dengan tingkat stres pada mahasiswa Program Studi S1 Keperawatan Fakultas Keperawatan Universitas Nahdlatul Ulama Surabaya.

3. Manajemen Waktu dengan Tingkat Stres Berdasarkan tabel 4.9 menunjukkan bahwa dari 240 responden didapatkan sebagian besar $(52,5 \%)$ mempunyai manajemen waktu tidak baik memiliki tingkat stres berat. Tabel 4.10 menunjukkan bahwa dari hasil uji Pearson Chi-Square dengan nilai kemaknaan $\alpha=0,05$, didapatkan nilai $\mathrm{p}$ value $=0,947$ yang berarti $\quad \mathrm{p}$-value $>\alpha$ maka $\mathrm{H}_{1}$ ditolak, artinya manajemen waktu tidak berhubungan dengan tingkat stres pada mahasiswa Program Studi S1 Keperawatan Fakultas Keperawatan Universitas Nahdlatul Ulama Surabaya.

Mufadhal, Barseli, dkk (2017) menyatakan bahwa individu yang berpikir tidak dapat mengendalikan situasi, cenderung mengalami stres lebih besar. Semakin besar kendali bahwa ia dapat melakukan sesuatu, semakin kecil kemungkinan stres yang akan dialami oleh mahasiswa. Hal ini sejalan dengan bahwa sesuai penelitian mahasiswa tidak mampu memanajemen waktunya dengan baik, tetapi dalam penelitian ini manajemen waktu yang tidak baik tidak menimbulkan stres akademik bagi mahasiswa. Menurut peneliti mahasiswa stres yang dialaminya bukan dikarenakan oleh manajemen waktu untuk mengurus tugas yang berhubungan dengan perkuliahan, tetapi ada hal lain yang membuat mahasiswa berada dalam kategori stres berat.

\section{KESIMPULAN}

Pada penelitian ini dapat disimpulkan beberapa hal diantaranya : sebagian besar mahasiswa Program Studi S1 Keperawatan berada pada rentang tingkat stress berat, pertumbuhan fisik (IMT) tidak berhubungan dengan tingkat stress dan manajemen waktu tidak berhubungan dengan tingkat stress.

\section{DAFTAR PUSTAKA}

Agolla, J.E \& Ongori, H. (2009). An assassment of academic stress among undergraduate students. Academic journals, Educational research and review. Vol 4(2), pp.063-067. Diunduh dari http://www.library.unusa.ac.id pada tanggal 21 Februari 2018 pukul 20.00 WIB

Astarini, Made Indra Ayu, Yusuf,Ah, Purwaningsih (2017). Relationship Centered Care dengan Metode Preceptorship untuk Menurunkan Stres dan Meningkatkan Perilaku Caring Mahasiswa Profesi Ners. Jurnal 
Penelitian Kesehatan Suara Forikes. Volume VIII Nomor 4 Oktober 2017. Diunduh dari http://www.googlescholar.com pada tanggal 21 Februari 2018 pukul 14.00 WIB

Braham (1990). Gejala Stres. Indonesian Psychological Journal. Anima. No.48. Volume XII. Juli September 1997.

Britton, B.K \& Tesser, A. (1991). Effects of Time Management Practices on Collage Grades. Journal of Educational Psychology. Diunduh dari website http://www.googlescholar.com pada tanggal 05 Maret 2018 jam 08.30 WIB.

Crowford, J.C \& Henry, J.D. (2003). The Depression Anxiety Stress Scale (DASS) : Normative data and latent structure in a large non clinical sample. British Journal of Clinical Psycology, 42, 111-131. Diunduh dari website http://www.googlescholar.com pada tanggal 05 Maret 2018 jam 08.30 WIB.

Davidson, J.(2001). Manajemen Waktu. Yogyakarta : Andi

Fitriah, Naila (2014). Manajemen Waktu Belajar Mahasiswa Keperawatan dalam Melaksanakan Metode Problem Based Learning (PBL) di Universitas Islam Negeri Syarif Hidayatullah Jakarta. Skripsi. Diunduh dari website http://www.googlescholar.com pada tanggal 05 Maret 2018 jam 08.30 WIB.

Govarest, S \& Gregoire, J. (2004). Stressfull academic situasions : study on appraisal variables in adolescence. British Journal of Clinical Psycology, 54, 261-271. Diunduh dari http://www.googlescholar.com pada tanggal 06 Maret 2018 pukul 10.00 WIB
Hatmanti, Nety Mawarda. (2015). Tingkat Stres dengan Siklus Menstruasi pada Mahasiswa. Jurnal Ilmiah Kesehatan. Vol.8 No.1. Diunduh dari website http:www.googlescholar.com pada tanggal 10 Agustus 2018 pukul 10.00 WIB.

Hou, Linping, Liu, Yaozhong. (2016). The Influence of Stressful Life Events of College Students on Subjective WellBeing : The Mediation Effect of the Operational Effectiveness. Open Journal of Sosial Sciences 2016 page 70-76. Diunduh dari http://www.file.scirp.org pada tanggal 21 Februari 2018 pukul 13.00 WIB

Kusuma, Henni. (2011). Hubungan antara Depresi dan Dukungan Keluarga dengan Kualitas Hidup Pasien HIV/AIDS yang Menjalani Perawatan di RSUPN Cipto Mangunkusumo Jakarta. Tesis. Universitas Indonesia. Diunduh dari http://www.googlescholar.com pada tanggal 06 Maret 2018 pukul 10.00 WIB

Mufadhal, Barseli; Ifdil; Nikmarijal (2017). Konsep Stres Akademik Siswa. Jurnal Konseling dan Pendidikan. Volume 5 Nomor 3 Halaman 143-148. Diunduh dari website http:www.google.com pada tanggal 5 Januari 2019 pukul $09.00 \mathrm{WIB}$

Nasution, Indri Kemala (2007). Stres pada Remaja. Makalah. USU Repository. Diunduh dari website http:www.google.com pada tanggal 5 Januari 2019 pukul 09.00 WIB

Oxford, J. (1992). Community Psychology : Theory \& Practice. New York : John Willey \& Sons Inc. Dilihat dari http://www.googlebook.com pada tanggal 06 Maret 2018 pukul 12.00 WIB 
Purwati, Susi. (2012). Tingkat Stres Akademik pada Mahasiswa Reguler Angkatan 2010 Fakultas Ilmu Keperawatan Universitas Indonesia. Skripsi. Tidak dipublikasikan. Diunduh dari website http:www.google.com pada tanggal 5 Januari 2019 pukul 09.00 WIB

Rahmawati, Ade (2006). Harga Diri pada Remaja Obesitas. Makalah. USU Repository. Diunduh dari website http:www.google.com pada tanggal 5 Januari 2019 pukul 09.00 WIB

Slamet, Suprapti I.S, Sumarmo Markom (2003). Pengantar Psikologi Klinis.
Jakarta : Universitas Indonesia (UIPress).

Smet, K.G. (2004). Social Support Survei. Journal of Social Science \& Medicine : 32 (705-706). Diunduh dari http://www.googlescholar.com pada tanggal 06 Maret 2018 pukul 12.00 WIB

Zyga, S. (2013). Stress in Nursing Students. Internasional Journal of Caring Science. 6 (1). Diunduh dari http://www.googlescholar.com pada tanggal 21 Februari 2018 pukul 14.00 WIB 